\title{
Etiology and Prevention of Gastric Cancer
}

\author{
Xiao Jiao Cheng Jia Cheng Lin Shui Ping Tu \\ Department of Oncology, Renji Hospital, School of Medicine, Shanghai Jiaotong University, \\ Shanghai, China
}

\section{Key Words}

Cancer prevention · Gastric cancer · Helicobacter pylori · Premalignant condition

\begin{abstract}
Background: Gastric cancer is a heterogeneous malignant disease associated with environmental and genetic predisposing factors. While gastric cancer incidence and mortality fell greatly globally over the past decades, it remains the fourth cause of cancer-related death worldwide. Thus, prevention of gastric cancer is still a major strategy for improvement of gastric cancer prognosis. Summary: Helicobacter pylori infection has been demonstrated to be a major risk factor for the development of gastric cancer. Unhealthy diet and lifestyle, including high-salt food, smoking and drinking, are able to induce genotypic and phenotypic transformation of gastric epithelial cells. Gene mutations (such as E-cadherin) in stomach epithelial cells are major genetic causes for gastric cancer. The eradication of $H$. pylori has been demonstrated to be an effective approach for primary prevention of gastric cancer. Increased intake of a diet rich in vegetables and fresh fruits as well as smoking cessation have been shown to reduce the incidence of gastric cancer. The secondary prevention strategy is to screen premalignant gastric lesions by endoscopy. Biomarker tests are also reliable methods to identify gastric precancerous lesions. Endoscopy screening is still the gold standard for diagnosis of gastric cancer. Key Message: $H$. pylori infection, a diet rich in salted and/or smoked food and red meat, as well as gene mutations are major risk factors for the development of gastric cancer. Practical Implications: The eradication of $H$. pylori is a major primary preventive strategy of gastric cancer. A healthy lifestyle, including increased intake of a diet rich in fruit and vegetables, reduced intake of salted and smoked food and red meat, a reduction of alcohol intake as well as smoking cessation will be effective approaches for the prevention of gastric cancer.




\section{Introduction}

Although the incidence of gastric cancer has greatly decreased in Western countries, it is still one of the most common cancers in Asia. In China, gastric cancer is the third most common cancer after lung cancer, liver cancer in men and lung cancer, breast cancer in women, and the third leading cause of cancer-related death [1]. To reduce gastric cancer mortality, prevention is the critical approach for improvement of gastric prognosis. This article will discuss the epidemiology, general risk factors and prevention of gastric cancer by reviewing the classic studies and also the new findings over the past few years.

There are several types of cancers arising from the stomach. The majority (about 90\%) of stomach cancers belong to the group of adenocarcinomas, which originate from the glands of the gastric mucosa. Besides adenocarcinomas, other types of cancers may arise from lymphoid tissue and muscles of the stomach. For example, mucosa-associated lymphoid tissue lymphomas are derived from gastric lymphoid tissues, and leiomyosarcomas originate from the muscles below the mucosa. In this review, we will focus on gastric adenocarcinomas.

According to the Lauren classification [2], gastric adenocarcinomas can be classified into two major types: intestinal type and diffuse type. The intestinal type of gastric cancer is associated with Helicobacter pylori infection with gastric intestinal metaplasia and atrophy, whereas the diffuse type of gastric cancer originates from pangastritis without atrophy. According to the different anatomic sites, gastric adenocarcinomas are divided into cardia and non-cardia gastric cancers. The majority of gastric cancers are non-cardia cancers. The non-cardia gastric cancers have been increasing since the 1970s [3]. Noncardia and cardia adenocarcinomas have very different biological characteristics.

Non-cardia gastric cancer is more common in males (twice as common as in women), blacks, older people, lower socioeconomic groups and developing countries [3, 4]. In China, the proportions of proximal gastric cancer were low, up to approximately one third [5]. In contrast, cardia gastric cancer has a male:female ratio of approximately 5:1.

Around one million new cases of gastric cancer were diagnosed worldwide according to Globocan 2012, making gastric cancer the fifth most common malignancy worldwide, after lung, breast, colorectal and prostate cancer. However, the incidence rate of gastric cancer has decreased worldwide [6]. In the USA, the incidence rate of gastric cancer decreased by $1.7 \%$ for men and $0.8 \%$ for women annually from 1992 to 2010 [7]. The highest incidence rate of gastric cancer occurs in Eastern Asia, Eastern Europe and South America, whereas the lowest rate of gastric cancer is found in North America and most parts of Africa [8]. While an overall decrease of gastric cancer incident rates has been observed in China, the decline was much less than in other countries. Moreover, gastric cancer incident rates are increased in the younger and older groups [9].

While the incidence of gastric cancer has declined worldwide, the overall relative 5 -year survival rate is only approximately $30 \%$ in most parts of the world [10]. In Japan, due to the effectiveness of its mass screening programs, the 5-year survival rates of stage I and II gastric cancer have been reported to be up to $70 \%[11,12]$. In China, the 5 -year relative survival rate of gastric cancer has improved much over the last century, but it remains lower than 35\% [13]. Gastric cancer is still the fourth leading cause of cancerrelated death worldwide $[6,9]$. Thus, prevention is a key strategy for reduction of gastric cancer-related mortality. 


\section{Risk Factors for Gastric Cancer}

Gastric cancer is a genetically heterogeneous tumor with multifactorial etiologies, associated with environmental and genetic factors. Many factors play important roles in the development of gastric cancer. Among these, inherited genetic factors, H. pylori infection, dietary factors and lifestyle factors are strongly linked to gastric cancer $[7,14]$.

\section{Hereditary and Genetic Factors}

While hereditary gastric cancer is uncommon, genetic alterations in sporadic gastric cancer cases are frequently reported. Any family with two recognized causes of gastric cancer in the first- or second-degree relatives, with the tumor occurring in at least one member under the age of 50 years, or in three members in the first- or second-degree relatives at any age must be considered as genetically predisposed to gastric cancer. While genetic factors have been proposed to play important roles in gastric carcinogenesis by possibly affecting inflammatory and immune responses especially to $H$. pylori infection and thus altering susceptibility to gastric cancer, however, so far few high-penetrance genes have been identified for gastric cancer development.

Interleukin $1 \beta$ gene $(I L-1 \beta)$ has been recognized as an important gene that contributes to initiation and amplification of inflammatory response. Polymorphisms of $I L-1 \beta$ and of the interleukin 1 receptor antagonist $(I L-1 R N)$ gene have been associated with gastric cancer risk [15]. Results from very large genome-wide association studies showed reproducible relationships between single nucleotide polymorphisms located at Mucin 1, cell surface-associated gene (MUC1) genes, prostate stem cell antigen gene (PSCA) and PLCE1 with different subtypes of gastric cancer risk. These results of genome-wide association studies are mainly from Chinese, Korean and Japanese populations, but the biological mechanisms involved in these polymorphisms are still not completely understood [7].

\section{H. pylori Infection}

H. pylori, a Gram-negative bacterium, has been characterized as a class I carcinogen of gastric cancer by the World Health Organization since 1994 [16]. H. pylori colonizes the gastric mucosa in $50 \%$ of the human population. Many epidemiological and classic studies have shown that $H$. pylori infection is the main risk factor of gastric cancer [17-21]. The oncogenic effects of $H$. pylori infection have been demonstrated through two major mechanisms: the direct epigenetic effects of $H$. pylori on gastric epithelial cells and the indirect inflammatory response of $H$. pylori on the gastric mucosa [16]. Certain $H$. pylori strains with the virulence factor (such as cytotoxin-associated gene A, CagA) are more likely to increase gastric cancer risk.

Many studies have shown that $\operatorname{cag} A$ virulence factors and vacuolating cytotoxin $\mathrm{A}$ in the cag pathogenicity island are linked to colonization and pathogenicity of $H$. pylori. cagA has been demonstrated to be associated with inhibition of p53 function, in a manner similar to human papillomavirus and other oncogenic DNA viruses [22]. The vacA encodes a secreted bacterial toxin (VacA) and induces multiple structural and functional alterations in gastric epithelial cells [23]. H. pylori strains with cagA and/or vacA are associated with increased risk for developing both intense tissue responses and premalignant and malignant lesions in the distal stomach through secreting a functional cytotoxin [24, 25].

\section{Dietary Factors}

The relationship between dietary factors and gastric cancer risk has been widely investigated. The World Cancer Research Fund/American Institute for Cancer Research (WCRF/ AICR) concluded that vegetables and fruits probably protect against gastric cancer, whereas 
salt and salt-preserved foods as well as smoked foods, processed, grilled (broiled) and barbecued (charbroiled) animal meets are probably causes of gastric cancer [26].

Some large cohort studies in Korea have shown that people who prefer salty food have a higher risk for gastric cancer [27]. Intake of salted foods has been demonstrated to enhance the risk of $H$. pylori infection and, even worse, to increase the capability of $H$. pylori to promote gastric cancer development by enhancing cagA expression [28].

Food carcinogens can also interact directly with the gastric epithelial cells and cause gene mutation of epithelial cells. A high level of sodium chloride has been shown to damage the gastric mucosa, cause cell death and induce regenerative cell proliferation in animal models $[29,30]$, finally resulting in inflammation and injury such as diffuse erosion and degeneration [31]. High-salt diet has been found to be associated with colonization of $H$. pylori 56 and to exacerbate $H$. pylori-induced inflammation [32], which is consequently responsible for gastric carcinogenesis promotion in a dose-dependent manner [33]. This result is confirmed in other studies showing that a high level of salt synergistically increases the expression of pro-inflammatory enzymes and cytokines in gastric mucosa with $H$. pylori infection [34]. High salt stimulation enhances expression of $H$. pylori cagA and enhanced ability of $H$. pylori to alter gastric epithelial cell function [35].

$\mathrm{N}$-nitroso compounds are another dietary factor that might play a role in gastric carcinogenesis. Nitrates are endogenously produced in gastric acid and are likely to contribute to $\mathrm{N}$-nitroso compound production and exposure; they are recognized as mutagens and carcinogens [26]. Dietary or endogenous exposure to $N$-nitroso compounds has been demonstrated to significantly increase gastrointestinal cancer risk, especially with non-cardia gastric cancer rather than cardia gastric cancer [36, 37]. Many processed meats contain high levels of salt and nitrite. Red meat has been shown to promote the formation of $N$-nitroso compounds through direct reaction between nitric oxide and hemoglobin and myoglobin [36]. Red meat also contains iron, which can lead to the production of free radicals.

\section{Roles of Smoking and Alcohol Habits}

Among environmental factors, a variety of habits play important roles in gastric cancer development. The roles of smoking and alcohol intake have been paid mostattention as important high-risk factors for gastric cancer. In a study of the role of $H$. pylori infection in gastric cancer development, current smoking showed a higher risk for gastric cancer $(\mathrm{RR}=2.3,95 \% \mathrm{CI} 1.4-3.5$, $\mathrm{p}<0.001)$, with more diffuse-type than intestinal-type tumors $(\mathrm{p}<0.05)$. In a prospective cohort of 18,244 middle-aged men in Shanghai over 20 years of follow-up, 391 gastric cancer cases were diagnosed. Smokers had an increased risk of gastric cancer (HR = 1.59, 95\% CI 1.27-1.99) compared to non-smokers after adjustment for alcohol intake and other confounders.

Smokers exhibited an $80 \%$ increase in the risk of gastric cancer $(\mathrm{HR}=1.81,95 \%$ CI $1.36-$ 2.41) among non-drinkers. On the contrary, heavy drinkers showed a statistically significant increase in the risk of gastric cancer ( $\mathrm{HR}=1.46,95 \% \mathrm{CI} 1.05-2.04)$ among all subjects and a statistically non-significantly $80 \%$ increase in the risk among smokers [38]. In a cohort study of 7,150 men in Lithuania over 30 years, 185 cases of gastric cancer were found. A higher intake of wine $>0.5$ liter per occasion compared to less drinking was associated with a high risk of gastric cancer with a HR of 2.95 for men (95\% CI 1.30-6.68) [39]. In an European prospective nutrition cohort study with the occurrence of 444 cases of gastric cancer, heavy alcohol consumption at baseline was positively associated with gastric cancer risk ( $\mathrm{HR}=1.65$, 95\% CI 1.06-2.58), whereas lower consumption ( $<60 \mathrm{~g} /$ day) was not [40]. Intestinal noncardia carcinoma was associated with heavy alcohol intake.

Other risk factors, including positive family history, radiation exposure, older age, male sex, lack of physical activity and low socioeconomic status, have also been associated with increased risk of both non-cardia and cardia gastric cancer, whereas gastroesophageal reflux 
disease and obesity have specifically been related to increased risk of cardia gastric cancer [7]. However, non-steroidal anti-inflammatory drugs (NSAIDs) and statin intake have inverse relations with gastric cancer risk [7].

\section{Epstein-Barr Virus Infection}

Besides H. pylori, another infectious agent is the Epstein-Barr virus (EBV), which has been associated with gastric cancer. EBV is a ubiquitous infectious agent with a prevalence of $>90 \%$ in adults. EBV has been causally associated with the development of several malignancies, including nasopharyngeal carcinoma, Hodgkin's lymphoma, Burkitt's lymphoma and immunosuppression-related lymphoma [41]. Around 8\% of gastric cancers have been estimated to harbor EBV, however there is insufficient epidemiological evidence to show a clear etiological role for EBV in gastric carcinogenesis [42]. The EBV genome exists in the tumor cells in a monoclonal form, and transforming EBV proteins are expressed in the tumor cells. A meta-analysis has shown that the percentage of EBV-positive gastric cancer varies according to age, sex and anatomic subsite. EBV positivity decreased with age among male cases [43]. EBV-positive gastric cancer with longer survival may have distinct clinical and genetic features, and therefore may be a separate clinical type.

\section{Prevention Strategies for Gastric Cancer}

The prevention strategies for gastric cancer include the intervention of gastric cancer etiology (such as H. pylori eradication and changes in lifestyle) and early detection and treatment of gastric cancer.

\section{Eradication of H. pylori}

Since $H$. pylori infection is the main cause of gastritis and precancerous conditions (atrophic gastritis, intestinal metaplasia and dysplasia), its eradication is a reasonable strategy for gastric cancer prevention. Many meta-analyses have demonstrated that $H$. pylori eradication can reverse intestinal metaplasia and reduce the risk for gastric cancer [44]. A meta-analysis of seven randomized clinical trials showed that eradication treatment of $H$. pylori can reduce gastric cancer risk by $35.3 \%$ [45]. Another meta-analysis of six reported randomized clinical studies in healthy asymptomatic adults showed that $H$. pylori can reduce gastric cancer risk by $30.4 \%$ [46]. A French clinical trial exhibited a statistically significant decrease in gastric cancer risk following 2-week antibiotic treatment for H. pylori. Short-term treatment with omeprazole and amoxicillin significantly reduced gastric cancer incidence by $39 \%$ after 14.7 years of follow-up [47]. The Asia-Pacific Gastric Cancer Consensus has recommended screening for and treatment of $H$. pylori infection in regions with high incidence of gastric cancer as an effective preventive strategy for gastric cancer [48]. A randomized controlled trial showed that $H$. pylori eradication prevented gastric cancer in a high-risk region of China [49]. In that study, among 1,630 healthy carriers of $H$. pylori infection, 18 new cases of gastric cancer were diagnosed. No overall reduction was observed in all participants who received $H$. pylori eradication treatment $(\mathrm{n}=7)$ compared with those who did not $(\mathrm{n}=$ 11) $(\mathrm{p}=0.33)$. However, in a subgroup of patients with no precancerous lesions on presentation, no patient developed gastric cancer during a follow-up of 7.5 years after $H$. pylori eradication treatment compared with those who received placebo ( 0 vs. $6, p=0.02$ ).

However, gastric cancer development cannot be easily prevented by the eradication of H. pylori when the gastritis has progressed to advanced precancerous conditions. As the development of gastric precancerous disease to gastric cancer usually takes a long time and occurs at an older age, $H$. pylori eradication must be conducted long before the atrophic 
gastritis associated with intestinal metaplasia develops. It means that the eradication of H. pylori could have a preventive effect on gastric cancer only when eradication is performed at an earlier age. In an double-blind randomized prospective controlled study, successful eradication of $H$. pylori did not lead to regression, but ended the progression of intestinal metaplasia after 4.5 years compared to the non-eradicated group [50].

Since gastritis is a very common disease in most developing countries and few subjects develop gastric cancer, mass eradication of $\mathrm{H}$. pylori in all members of these societies with a high prevalence of infection, even in areas with high risk for gastric cancer, seems to be unfeasible. Besides high costs, various side effects of eradication therapy and the occurrence of H. pylori drug resistance must be taken into consideration. Furthermore, recent studies have found that the development of esophageal and cardia cancer as well as esophagitis are associated with negative $H$. pylori infection $[51,52]$. Thus, the advantage of $H$. pylori eradication must be evaluated against the probable hazard in any individual, which can occur many years or some decades later. H. pylori eradication should be conducted in the first-degree relatives of gastric cancer patients and in those having an individually high risk of developing gastric cancer, like patients with corpus-dominant gastritis. Therefore, the long-term consequences of interventional $H$. pylori eradication in the population for gastric cancer prevention remain to be further studied.

\section{Chemoprevention of Gastric Cancer}

So far, no randomized controlled studies are present about the long-term effects of NSAIDs alone on gastric cancer development. In a meta-analysis of eight case-control studies and one cohort study with a total of 2,831 gastric cancer patients, NSAID users had a reduced risk of gastric cancer, with an OR of 0.78 (95\% CI 0.69-0.87). Users of aspirin only (OR $=0.73$, 95\% CI 0.63-0.86) and non-aspirin NSAIDs (OR $=0.74,95 \%$ CI $0.55-1.00$ ) showed a similar reduction in gastric cancer risk [28]. The anti-angiogenesis and apoptosis-promoting effects of NSAIDs are likely to play roles in the inhibition of gastric carcinogenesis [53]. Some ongoing cohort and population studies for the prevention of gastric cancer, including low-dose aspirin, were administered to subjects in different countries [54]. The results of those large and longterm studies will clarify the effect of aspirin on the prevention of gastric cancer in the future.

One study [53] investigated the preventive effect of etodolac, a selective cyclooxygenase 2 inhibitor, on metachronous cancer development after endoscopic resection of early gastric cancer. Among 267 early gastric cancer patients who underwent endoscopic resection, 47 patients with extensive metaplastic gastritis were selected based on endoscopic examination. Non-randomized etodolac treatment ( $300 \mathrm{mg} /$ day) was administered to 26 patients (group A), while the remaining 21 patients were left untreated (group B). Patients were followed for metachronous cancer development with endoscopy every 6-12 months for up to 5 years $(4.2$ \pm 0.9 years). The results showed that five cancers developed in group $\mathrm{B}$ (incidence rate $=$ $6,266 / 100,000$ person-years), significantly more than the one cancer in group A (incidence rate $=898 / 100,000$ person-years; $p<0.05$ ). Long-term etodolac treatment did not influence the extent of metaplastic gastritis as revealed by endoscopic findings or by serum PG levels, but effectively reduced metachronous cancer development in patients with extensive metaplastic gastritis. These results strongly suggest that there is a potential for chemoprevention of cancer in the metaplastic stomach by using cyclooxygenase 2 inhibitor.

\section{Increased Intake of Vegetables and Fruits}

Sufficient fruit and vegetable intake has been demonstrated to reduce the prevalence of cancer in various organs, including gastrointestinal cancers. In a meta-analysis of clinical studies, a favorable effect on gastric cancer was found for a 'healthy diet' rich in vegetables and fruits. 
Dietary intervention should increase fruit and vegetable intake and reduce the consumption of salt or salt-preserved foods. In Korea, gastric cancer-related mortality was negatively associated with use of refrigerators and intake of fruit but not vegetables [55]. From a meta-analysis of 29 case-control studies conducted in Latin America, fruit and total vegetable consumption were each associated with a moderately reduced risk of gastric cancer [56]. In a case-control study from Italy, among the four major diets, named 'animal products', 'vitamins and fiber', 'vegetable unsaturated fatty acids' and 'starch-rich', gastric cancer risk was positively associated with the 'animal products' (OR $=2.13,95 \%$ CI 1.34-3.40, for the highest versus the lowest score quartile) and the 'starch-rich' dietary pattern (OR $=1.67,95 \% \mathrm{CI}$ 1.01-2.77), and negatively associated with 'vitamins and fiber' ( $\mathrm{OR}=0.60,95 \% \mathrm{CI} 1.01-2.77$ ) [57]. These results demonstrate that an increased intake of vegetables and fruits (Mediterranean diet) can prevent the development of gastric cancer.

Studies have shown that vitamin $\mathrm{C}$ may protect against $H$. pylori-associated gastric carcinogenesis by enhancing mucosal immune response, neutralizing free radicals, decreasing the formation of gastric $N$-nitroso compounds and influencing $H$. pylori growth [37]. The level of gastric juice vitamin $\mathrm{C}$ was also shown to be lower with infection with cagA-positive H. pylori strains compared with cagA-negative H. pylori strains [51]. The WCRF/AICR assesses other dietary factors and suggests that pulses (legumes) and foods containing selenium can protect against gastric cancer [26].

\section{Alteration of Lifestyle}

Since smoking has been demonstrated to be an important environmental factor for gastric cancer risk, smoking cessation would be a critical preventive strategy for gastric cancer development. Other lifestyle modifications such as decreased alcohol intake, increased fruit and vegetable intake, reduced salt intake, increased physical activity and a Mediterranean diet may help reduce the risk of getting gastric cancer.

\section{Endoscopy Screening}

While a critical strategy for gastric cancer prevention is to target prevention of risk factors, early diagnosis and treatment of precancerous diseases is also an important approach for gastric cancer prevention. Individuals with premalignant gastric lesions, including atrophic gastritis and intestinal metaplasia, have been defined as high-risk populations for gastric cancer [58]. These populations with high risk of cancer need special endoscopic surveillance at appropriate time intervals. Endoscopy is the best approach for detecting either precancerous lesions or gastric cancer and is widely used for gastric cancer screening in China, Japan, Korea and Venezuela. A population-based pilot study was conducted in Linqu County of China for detection of early gastric cancers to evaluate the prevalence of precancerous gastric lesions from 1989 to 1990 . A total of 3,400 residents (1,792 males, 1,608 females) aged 35-64 years were selected randomly and enrolled, representing $77.6 \%$ of the eligible population in 14 villages [59]. A nationwide study showed that the annual incidence of gastric cancer increased gradually within 5 years after the diagnosis of premalignant conditions. The incidence of gastric cancer was $0.1 \%$ for patients with atrophic gastritis, $0.25 \%$ for patients with intestinal metaplasia, $0.6 \%$ for patients with mild to moderate dysplasia and $6 \%$ for patients with severe dysplasia [60]. Consensus guidelines developed by gastroenterology societies recommend that high-risk patients with extensive atrophy or intestinal metaplasia should be surveilled with endoscopy every 3 years [61].

Many methods can be used for screening and detecting early-stage gastric cancer. One of those is the use of photofluoroscopy, which has been conducted for gastric cancer screening in Japan since the 1960s [12]. Photofluoroscopy has been developed into a double-contrast method by combining a barium meal and air. The double-contrast method can provide better 
contrast shadow of early cancer lesions [12]. The data from five case-control studies and two cohort studies in Japan demonstrated that photofluoroscopy for gastric cancer screening can decrease gastric cancer mortality by $40-60 \%$ [12]. By now, many new advanced approaches providing better visualization of gastric mucosa lesions have been developed, such as chromoendoscopy [62], confocal laser endomicroscopy [63], narrow-band imaging endoscopy [64], magnifying endoscopy [65] and narrow-band imaging with magnifying endoscopy [66]. A large number of studies showed that these new advanced endoscopic imaging technologies have better accuracy for diagnosing premalignant gastric lesions than standard 'white light' endoscopy [67-69].

\section{Biomarker Screening of Individuals with High Risk for Gastric Cancer}

While endoscopic screening can diagnose early gastric cancer and reduce mortality of gastric cancer, it is an invasive examination and has possible side effects [70], including hemorrhage and perforation. Blood-based biomarker detection, as a non-invasive method, has been used for the detection of gastric precancerous lesions [71].

Serum pepsinogen testing is a widely used non-invasive method to screen for precancerous gastric lesions. The level of serum pepsinogen I (PgI) gradually declines during the development of atrophic gastritis, while the concentration of pepsinogen II (PgII) remains constant [72]. A low PgI level and a decreased PgI/PgII ratio mean gastric mucosal atrophy $[73,74]$. In addition, the combination of serum pepsinogen levels with anti-H. pylori IgG testing may better predict the risk of gastric cancer development. Low PgI (or PgI/PgII ratio) and negative $H$. pylori antibodies suggest the highest risk [75]. Recent studies showed that low serum ghrelin predicts high risk of gastric cancer [76, 77]. Gastrin-17 has been also considered as a biomarker for antral atrophy $[78,79]$. Trefoil factor 3 , a small and stable molecule secreted by the gastrointestinal tract, has been shown to be a better biomarker for both atrophy and gastric cancer than pepsinogens [80, 81]. In addition, anti-gastric parietal cell antibodies have been considered as independent biomarkers for gastric atrophy [82]. The combination detection of these biomarkers may increase the sensitivity and specify of prediction of gastric cancer development in high-risk populations.

\section{Conclusions}

Although the incidence of gastric cancer has decreased in developed countries, it remains a major disease with high mortality in developing countries [83]. In China, most gastric cancers are detected in their advanced stage [84]. Such a situation needs a more effective prevention strategy. Currently, the eradication of $H$. pylori remains a major approach for primary gastric cancer prevention, especially for the high-risk group with $\mathrm{H}$. pylori infection. In addition, changes in lifestyle and dietary habits could further help prevent gastric cancer incidence. The secondary prevention strategy needs more reliable screening approaches to find premalignant gastric lesions and early gastric cancer and conduct a personalized therapy for these lesions by endoscopy. Endoscopy screening is still the gold standard for diagnosis of gastric cancer and biomarker tests are also a reliable method to identify gastric precancerous lesions.

\section{Acknowledgment}

This work was funded by the National Natural Science Foundation of China (NSFC No. 81272403). 


\section{Disclosure Statement}

No potential conflicts of interest are disclosed.

\section{References}

1 Chen WQ, Zheng RS, Zhang SW, Zeng HM, Zou XN: The incidences and mortalities of major cancers in China, 2010. Chin J Cancer 2014;33:402-405.

-2 Lauren P: The two histological main types of gastric carcinoma: diffuse and so-called intestinal-type carcinoma. An attempt at a histo-clinical classification. Acta Pathol Microbiol Scand 1965;64:31-49.

3 Crew KD, Neugut AI: Epidemiology of gastric cancer. World J Gastroenterol 2006;12:354-362.

4 Cancer incidence in five continents. Volume VII. IARC Sci Publ 1997;143:i-xxxiv, 1-1240.

- 5 Strong VE, Wu AW, Selby LV, Gonen M, Hsu M, Song KY, Park CH, Coit DG, Ji JF, Brennan MF: Differences in gastric cancer survival between the U.S. and China. J Surg Oncol 2015;112:31-37.

-6 Bosetti C, Bertuccio P, Malvezzi M, Levi F, Chatenoud L, Negri E, La Vecchia C: Cancer mortality in Europe, 2005-2009, and an overview of trends since 1980. Ann Oncol 2013;24:2657-2671.

7 Karimi P, Islami F, Anandasabapathy S, Freedman ND, Kamangar F: Gastric cancer: descriptive epidemiology, risk factors, screening, and prevention. Cancer Epidemiol Biomarkers Prev 2014;23:700-713.

8 Forman D, Burley VJ: Gastric cancer: global pattern of the disease and an overview of environmental risk factors. Best Pract Res Clin Gastroenterol 2006;20:633-649.

-9 Jemal A, Siegel R, Ward E, Murray T, Xu J, Smigal C, Thun MJ: Cancer statistics, 2006. CA Cancer J Clin 2006;56: 106-130.

10 Park JY, von Karsa L, Herrero R: Prevention strategies for gastric cancer: a global perspective. Clin Endosc 2014; $47: 478-489$.

11 Isobe Y, Nashimoto A, Akazawa K, Oda I, Hayashi K, Miyashiro I, Katai H, Tsujitani S, Kodera Y, Seto Y, Kaminishi M: Gastric cancer treatment in Japan: 2008 annual report of the JGCA nationwide registry. Gastric Cancer 2011;14:301-316.

12 Hamashima C, Shibuya D, Yamazaki H, Inoue K, Fukao A, Saito H, Sobue T: The Japanese guidelines for gastric cancer screening. Jpn J Clin Oncol 2008;38:259-267.

13 Zheng L, Wu C, Xi P, Zhu M, Zhang L, Chen S, Li X, Gu J, Zheng Y: The survival and the long-term trends of patients with gastric cancer in Shanghai, China. BMC Cancer 2014;14:300.

14 Eid R, Moss SF: Helicobacter pylori infection and the development of gastric cancer. N Engl J Med 2002;346: 65-67.

15 Kamangar F, Cheng C, Abnet CC, Rabkin CS: Interleukin-1B polymorphisms and gastric cancer risk - a metaanalysis. Cancer Epidemiol Biomarkers Prev 2006;15:1920-1928.

-16 Ishaq S, Nunn L: Helicobacter pylori and gastric cancer: a state of the art review. Gastroenterol Hepatol Bed Bench 2015;8(suppl 1):S6-S14.

17 Asaka M, Takeda H, Sugiyama T, Kato M: What role does Helicobacter pylori play in gastric cancer? Gastroenterology 1997;113(6 suppl):S56-S60.

-18 An international association between Helicobacter pylori infection and gastric cancer. The EUROGAST Study Group. Lancet 1993;341:1359-1362.

19 de Vries AC, Kuipers EJ: Epidemiology of premalignant gastric lesions: implications for the development of screening and surveillance strategies. Helicobacter 2007;12(suppl 2):22-31.

-20 Huang JQ, Sridhar S, Chen Y, Hunt RH: Meta-analysis of the relationship between Helicobacter pylori seropositivity and gastric cancer. Gastroenterology 1998;114:1169-1179.

-21 de Martel C, Ferlay J, Franceschi S, Vignat J, Bray F, Forman D, Plummer M: Global burden of cancers attributable to infections in 2008: a review and synthetic analysis. Lancet Oncol 2012;13:607-615.

22 Buti L, Spooner E, van der Veen AG, Rappuoli R, Covacci A, Ploegh HL: Helicobacter pylori cytotoxin-associated gene A (CagA) subverts the apoptosis-stimulating protein of p53 (ASPP2) tumor suppressor pathway of the host. Proc Natl Acad Sci USA 2011;108:9238-9243.

-23 Gebert B, Fischer W, Haas R: The Helicobacter pylori vacuolating cytotoxin: from cellular vacuolation to immunosuppressive activities. Rev Physiol Biochem Pharmacol 2004;152:205-220.

-24 Saadat I, Higashi H, Obuse C, Umeda M, Murata-Kamiya N, Saito Y, Lu H, Ohnishi N, Azuma T, Suzuki A, Ohno S, Hatakeyama M: Helicobacter pylori CagA targets PAR1/MARK kinase to disrupt epithelial cell polarity. Nature 2007;447:330-333.

25 Peek RM Jr, Vaezi MF, Falk GW, Goldblum JR, Perez-Perez GI, Richter JE, Blaser MJ: Role of Helicobacter pylori $\operatorname{cagA}(+)$ strains and specific host immune responses on the development of premalignant and malignant lesions in the gastric cardia. Int J Cancer 1999;82:520-524.

-26 Wiseman M: The second World Cancer Research Fund/American Institute for Cancer Research expert report. Food, nutrition, physical activity, and the prevention of cancer: a global perspective. Proc Nutr Soc 2008;67: 253-256. 
27 Woo HD, Park S, Oh K, Kim HJ, Shin HR, Moon HK, Kim J: Diet and cancer risk in the Korean population: a metaanalysis. Asian Pac J Cancer Prev 2014;15:8509-8519.

28 Fox JG, Dangler CA, Taylor NS, King A, Koh TJ, Wang TC: High-salt diet induces gastric epithelial hyperplasia and parietal cell loss, and enhances Helicobacter pylori colonization in C57BL/6 mice. Cancer Res 1999;59: 4823-4828.

29 Cohen AJ, Roe FJ: Evaluation of the aetiological role of dietary salt exposure in gastric and other cancers in humans. Food Chem Toxicol 1997;35:271-293.

-30 Furihata C, Ohta H, Katsuyama T: Cause and effect between concentration-dependent tissue damage and temporary cell proliferation in rat stomach mucosa by $\mathrm{NaCl}$, a stomach tumor promoter. Carcinogenesis 1996; 17:401-406.

-31 Tsugane S, Sasazuki S, Kobayashi M, Sasaki S: Salt and salted food intake and subsequent risk of gastric cancer among middle-aged Japanese men and women. Br J Cancer 2004;90:128-134.

-32 Gaddy JA, Radin JN, Loh JT, Zhang F, Washington MK, Peek RM Jr, Algood HM, Cover TL: High dietary salt intake exacerbates Helicobacter pylori-induced gastric carcinogenesis. Infect Immun 2013;81:2258-2267.

33 Kato S, Tsukamoto T, Mizoshita T, Tanaka H, Kumagai T, Ota H, Katsuyama T, Asaka M, Tatematsu M: High salt diets dose-dependently promote gastric chemical carcinogenesis in Helicobacter pylori-infected Mongolian gerbils associated with a shift in mucin production from glandular to surface mucous cells. Int J Cancer 2006; 119:1558-1566.

-34 Toyoda T, Tsukamoto T, Hirano N, Mizoshita T, Kato S, Takasu S, Ban H, Tatematsu M: Synergistic upregulation of inducible nitric oxide synthase and cyclooxygenase-2 in gastric mucosa of Mongolian gerbils by a high-salt diet and Helicobacter pylori infection. Histol Histopathol 2008;23:593-599.

-35 Loh JT, Torres VJ, Cover TL: Regulation of Helicobacter pylori cagA expression in response to salt. Cancer Res 2007;67:4709-4715.

-36 Loh YH, Jakszyn P, Luben RN, Mulligan AA, Mitrou PN, Khaw KT: N-nitroso compounds and cancer incidence: the European Prospective Investigation into Cancer and Nutrition (EPIC)-Norfolk Study. Am J Clin Nutr 2011; 93:1053-1061.

-37 Jakszyn P, Bingham S, Pera G, Agudo A, Luben R, Welch A, Boeing H, Del Giudice G, Palli D, Saieva C, Krogh V, Sacerdote C, Tumino R, Panico S, Berglund G, Siman H, Hallmans G, Sanchez MJ, Larranaga N, Barricarte A, Chirlaque MD, Quiros JR, Key TJ, Allen N, Lund E, Carneiro F, Linseisen J, Nagel G, Overvad K, Tjonneland A, Olsen A, Bueno-de-Mesquita HB, Ocke MO, Peeters PH, Numans ME, Clavel-Chapelon F, Trichopoulou A, Fenger C, Stenling R, Ferrari P, Jenab M, Norat T, Riboli E, Gonzalez CA: Endogenous versus exogenous exposure to $\mathrm{N}$-nitroso compounds and gastric cancer risk in the European Prospective Investigation into Cancer and Nutrition (EPIC-EURGAST) study. Carcinogenesis 2006;27:1497-1501.

-38 Moy KA, Fan Y, Wang R, Gao YT, Yu MC, Yuan JM: Alcohol and tobacco use in relation to gastric cancer: a prospective study of men in Shanghai, China. Cancer Epidemiol Biomarkers Prev 2010;19:2287-2297.

-39 Everatt R, Tamosiunas A, Kuzmickiene I, Virviciute D, Radisauskas R, Reklaitiene R, Milinaviciene E: Alcohol consumption and risk of gastric cancer: a cohort study of men in Kaunas, Lithuania, with up to 30 years followup. BMC Cancer 2012;12:475.

40 Duell EJ, Travier N, Lujan-Barroso L, Clavel-Chapelon F, Boutron-Ruault MC, Morois S, Palli D, Krogh V, Panico S, Tumino R, Sacerdote C, Quiros JR, Sanchez-Cantalejo E, Navarro C, Gurrea AB, Dorronsoro M, Khaw KT, Allen NE, Key TJ, Bueno-de-Mesquita HB, Ros MM, Numans ME, Peeters PH, Trichopoulou A, Naska A, Dilis V, Teucher B, Kaaks R, Boeing H, Schutze M, Regner S, Lindkvist B, Johansson I, Hallmans G, Overvad K, Egeberg R, Tjonneland A, Lund E, Weiderpass E, Braaten T, Romieu I, Ferrari P, Jenab M, Stenling R, Aune D, Norat T, Riboli E, Gonzalez CA: Alcohol consumption and gastric cancer risk in the European Prospective Investigation into Cancer and Nutrition (EPIC) cohort. Am J Clin Nutr 2011;94:1266-1275.

41 Proceedings of the IARC Working Group on the Evaluation of Carcinogenic Risks to Humans. Epstein-Barr virus and Kaposi's sarcoma herpesvirus/human herpesvirus 8. Lyon, France, 17-24 June 1997. IARC Monogr Eval Carcinog Risks Hum 1997;70:1-492.

42 Demetriou CA, Straif K, Vineis P: From testing to estimation: the problem of false positives in the context of carcinogen evaluation in the IARC monographs. Cancer Epidemiol Biomarkers Prev 2012;21:1272-1281.

-43 Camargo MC, Murphy G, Koriyama C, Pfeiffer RM, Kim WH, Herrera-Goepfert R, Corvalan AH, Carrascal E, Abdirad A, Anwar M, Hao Z, Kattoor J, Yoshiwara-Wakabayashi E, Eizuru Y, Rabkin CS, Akiba S: Determinants of Epstein-Barr virus-positive gastric cancer: an international pooled analysis. Br J Cancer 2011;105:38-43.

44 Wang J, Xu L, Shi R, Huang X, Li SW, Huang Z, Zhang G: Gastric atrophy and intestinal metaplasia before and after Helicobacter pylori eradication: a meta-analysis. Digestion 2011;83:253-260.

45 Fuccio L, Zagari RM, Eusebi LH, Laterza L, Cennamo V, Ceroni L, Grilli D, Bazzoli F: Meta-analysis: can Helicobacter pylori eradication treatment reduce the risk for gastric cancer? Ann Intern Med 2009;151:121-128.

-46 Ford AC, Forman D, Hunt RH, Yuan Y, Moayyedi P: Helicobacter pylori eradication therapy to prevent gastric cancer in healthy asymptomatic infected individuals: systematic review and meta-analysis of randomised controlled trials. BMJ 2014;348:g3174.

47 Ma JL, Zhang L, Brown LM, Li JY, Shen L, Pan KF, Liu WD, Hu Y, Han ZX, Crystal-Mansour S, Pee D, Blot WJ, Fraumeni JF Jr, You WC, Gail MH: Fifteen-year effects of Helicobacter pylori, garlic, and vitamin treatments on gastric cancer incidence and mortality. J Natl Cancer Inst 2012;104:488-492. 
-48 Fock KM, Katelaris P, Sugano K, Ang TL, Hunt R, Talley NJ, Lam SK, Xiao SD, Tan HJ, Wu CY, Jung HC, Hoang BH, Kachintorn U, Goh KL, Chiba T, Rani AA; Second Asia-Pacific Conference: Second Asia-Pacific Consensus Guidelines for Helicobacter pylori infection. J Gastroenterol Hepatol 2009;24:1587-1600.

-49 Wong BC, Lam SK, Wong WM, Chen JS, Zheng TT, Feng RE, Lai KC, Hu WH, Yuen ST, Leung SY, Fong DY, Ho J, Ching CK: Helicobacter pylori eradication to prevent gastric cancer in a high-risk region of China: a randomized controlled trial. JAMA 2004;291:187-194.

-50 Massarrat S, Haj-Sheykholeslami A, Mohamadkhani A, Zendehdel N, Rakhshani N, Stolte M, Mirzaei M, Saliminejhad M, Saeidi S, Shahidi M: Precancerous conditions after H. pylori eradication: a randomized double blind study in first degree relatives of gastric cancer patients. Arch Iran Med 2012;15:664-669.

51 Rokkas T, Liatsos C, Petridou E, Papatheodorou G, Karameris A, Ladas SD, Raptis SA: Relationship of Helicobacter pylori CagA(+) status to gastric juice vitamin C levels. Eur J Clin Invest 1999;29:56-62.

52 Zhang ZW, Patchett SE, Perrett D, Katelaris PH, Domizio P, Farthing MJ: The relation between gastric vitamin C concentrations, mucosal histology, and CagA seropositivity in the human stomach. Gut 1998;43:322-326.

53 Dai Y, Wang WH: Non-steroidal anti-inflammatory drugs in prevention of gastric cancer. World J Gastroenterol 2006;12:2884-2889.

54 Sahin IH, Hassan MM, Garrett CR: Impact of non-steroidal anti-inflammatory drugs on gastrointestinal cancers: current state-of-the science. Cancer Lett 2014;345:249-257.

55 Park B, Shin A, Park SK, Ko KP, Ma SH, Lee EH, Gwack J, Jung EJ, Cho LY, Yang JJ, Yoo KY: Ecological study for refrigerator use, salt, vegetable, and fruit intakes, and gastric cancer. Cancer Causes Control 2011;22:14971502.

56 Bonequi P, Meneses-Gonzalez F, Correa P, Rabkin CS, Camargo MC: Risk factors for gastric cancer in Latin America: a meta-analysis. Cancer Causes Control 2013;24:217-231.

-57 Camargo MC, Kim WH, Chiaravalli AM, Kim KM, Corvalan AH, Matsuo K, Yu J, Sung JJ, Herrera-Goepfert R, Meneses-Gonzalez F, Kijima Y, Natsugoe S, Liao LM, Lissowska J, Kim S, Hu N, Gonzalez CA, Yatabe Y, Koriyama C, Hewitt SM, Akiba S, Gulley ML, Taylor PR, Rabkin CS: Improved survival of gastric cancer with tumour Epstein-Barr virus positivity: an international pooled analysis. Gut 2014;63:236-243.

58 Qureshi WA, Graham DY: Diagnosis and management of Helicobacter pylori infection. Clin Cornerstone 1999; 1:18-28.

-59 You WC, Blot WJ, Li JY, Chang YS, Jin ML, Kneller R, Zhang L, Han ZX, Zeng XR, Liu WD, et al: Precancerous gastric lesions in a population at high risk of stomach cancer. Cancer Res 1993;53:1317-1321.

60 de Vries AC, van Grieken NC, Looman CW, Casparie MK, de Vries E, Meijer GA, Kuipers EJ: Gastric cancer risk in patients with premalignant gastric lesions: a nationwide cohort study in the Netherlands. Gastroenterology 2008;134:945-952.

61 Dinis-Ribeiro M, Areia M, de Vries AC, Marcos-Pinto R, Monteiro-Soares M, O'Connor A, Pereira C, PimentelNunes P, Correia R, Ensari A, Dumonceau JM, Machado JC, Macedo G, Malfertheiner P, Matysiak-Budnik T, Megraud F, Miki K, O’Morain C, Peek RM, Ponchon T, Ristimaki A, Rembacken B, Carneiro F, Kuipers EJ: Management of precancerous conditions and lesions in the stomach (MAPS): guideline from the European Society of Gastrointestinal Endoscopy (ESGE), European Helicobacter Study Group (EHSG), European Society of Pathology (ESP), and the Sociedade Portuguesa de Endoscopia Digestiva (SPED). Endoscopy 2012;44: 74-94.

62 Neumann H, Fujishiro M, Wilcox CM, Monkemuller K: Present and future perspectives of virtual chromoendoscopy with i-scan and optical enhancement technology. Dig Endosc 2014;26(suppl 1):43-51.

63 Pirogov SS, Sokolov VV, Karpova ES, Pavlov PV, Volchenko NN, Kaprin AD: Early gastric cancer and precancerous conditions diagnostics with confocal laser endomicroscopy (in Russian). Eksp Klin Gastroenterol 2014; $3: 18-24$

64 Kawai T, Yanagizawa K, Naito S, Sugimoto H, Fukuzawa M, Gotoda T, Matsubayashi J, Nagao T, Hoshino S, Tsuchida A, Moriyasu F: Evaluation of gastric cancer diagnosis using new ultrathin transnasal endoscopy with narrow-band imaging: preliminary study. J Gastroenterol Hepatol 2014;29(suppl 4):33-36.

65 Kawamura M, Sekine H, Abe S, Shibuya D, Kato K, Masuda T: Clinical significance of white gastric crypt openings observed via magnifying endoscopy. World J Gastroenterol 2013;19:9392-9398.

66 Boeriu A, Boeriu C, Drasovean S, Pascarenco O, Mocan S, Stoian M, Dobru D: Narrow-band imaging with magnifying endoscopy for the evaluation of gastrointestinal lesions. World J Gastrointest Endosc 2015;7:110-120.

-67 Qumseya BJ, Wang H, Badie N, Uzomba RN, Parasa S, White DL, Wolfsen H, Sharma P, Wallace MB: Advanced imaging technologies increase detection of dysplasia and neoplasia in patients with Barrett's esophagus: a meta-analysis and systematic review. Clin Gastroenterol Hepatol 2013;11:1562-1570.e1-2.

68 Yu H, Yang AM, Lu XH, Zhou WX, Yao F, Fei GJ, Guo T, Yao LQ, He LP, Wang BM: Magnifying narrow-band imaging endoscopy is superior in diagnosis of early gastric cancer. World J Gastroenterol 2015;21:9156-9162.

69 Zhang Q, Wang F, Chen ZY, Wang Z, Zhi FC, Liu S, Bai Y: Comparison of the diagnostic efficacy of white light endoscopy and magnifying endoscopy with narrow band imaging for early gastric cancer: a meta-analysis. Gastric Cancer 2015, Epub ahead of print.

70 Bretthauer M, Kalager M, Adami HO: Do's and don'ts in evaluation of endoscopic screening for gastrointestinal cancers. Endoscopy 2016;48:75-80.

71 Storskrubb T, Aro P, Ronkainen J, Sipponen P, Nyhlin H, Talley NJ, Engstrand L, Stolte M, Vieth M, Walker M, Agreus L: Serum biomarkers provide an accurate method for diagnosis of atrophic gastritis in a general population: The Kalixanda study. Scand J Gastroenterol 2008;43:1448-1455. 
Ren JS, Kamangar F, Qiao YL, Taylor PR, Liang H, Dawsey SM, Liu B, Fan JH, Abnet CC: Serum pepsinogens and risk of gastric and oesophageal cancers in the General Population Nutrition Intervention Trial cohort. Gut 2009;58:636-642.

73 Zoalfaghari A, Aletaha N, Roushan N, Taslimi R, Foroutan H, Faridnia B: Accuracy of pepsinogens for early diagnosis of atrophic gastritis and gastric cancer in Iranian population. Med J Islam Repub Iran 2014;28:150.

-74 Hattori Y, Tashiro H, Kawamoto T, Kodama Y: Sensitivity and specificity of mass screening for gastric cancer using the measurement of serum pepsinogens. Jpn J Cancer Res 1995;86:1210-1215.

-75 Watabe H, Mitsushima T, Yamaji Y, Okamoto M, Wada R, Kokubo T, Doi H, Yoshida H, Kawabe T, Omata M: Predicting the development of gastric cancer from combining Helicobacter pylori antibodies and serum pepsinogen status: a prospective endoscopic cohort study. Gut 2005;54:764-768.

76 Murphy G, Kamangar F, Dawsey SM, Stanczyk FZ, Weinstein SJ, Taylor PR, Virtamo J, Abnet CC, Albanes D, Freedman ND: The relationship between serum ghrelin and the risk of gastric and esophagogastric junctional adenocarcinomas. J Natl Cancer Inst 2011;103:1123-1129.

77 Sadjadi A, Yazdanbod A, Lee YY, Boreiri M, Samadi F, Alizadeh BZ, Islami F, Fyfe V, Babaei M, Namazi MJ, Going JJ, Sotoudeh M, de Bock GH, Malekzadeh R, Derakhshan MH: Serum ghrelin; a new surrogate marker of gastric mucosal alterations in upper gastrointestinal carcinogenesis. PLoS One 2013;8:e74440.

78 Agreus L, Kuipers EJ, Kupcinskas L, Malfertheiner P, Di Mario F, Leja M, Mahachai V, Yaron N, van Oijen M, Perez Perez G, Rugge M, Ronkainen J, Salaspuro M, Sipponen P, Sugano K, Sung J: Rationale in diagnosis and screening of atrophic gastritis with stomach-specific plasma biomarkers. Scand J Gastroenterol 2012;47:136147.

79 Leja M, Kupcinskas L, Funka K, Sudraba A, Jonaitis L, Ivanauskas A, Janciauskas D, Kuidelis G, Chiu HM, Lin JT: Value of gastrin-17 in detecting antral atrophy. Adv Med Sci 2011;56:145-150.

-80 Aikou S, Ohmoto Y, Gunji T, Matsuhashi N, Ohtsu H, Miura H, Kubota K, Yamagata Y, Seto Y, Nakajima A, Goldenring JR, Kaminishi M, Nomura S: Tests for serum levels of trefoil factor family proteins can improve gastric cancer screening. Gastroenterology 2011;141:837-845.e1-7.

81 Huang Z, Zhang X, Lu H, Wu L, Wang D, Zhang Q, Ding H: Serum trefoil factor 3 is a promising non-invasive biomarker for gastric cancer screening: a monocentric cohort study in China. BMC Gastroenterol 2014;14:74.

82 Zhang Y, Weck MN, Schottker B, Rothenbacher D, Brenner H: Gastric parietal cell antibodies, Helicobacter pylori infection, and chronic atrophic gastritis: evidence from a large population-based study in Germany. Cancer Epidemiol Biomarkers Prev 2013;22:821-826.

-83 Bray F, Ren JS, Masuyer E, Ferlay J: Global estimates of cancer prevalence for 27 sites in the adult population in 2008. Int J Cancer 2013;132:1133-1145.

-84 Siegel R, Ma J, Zou Z, Jemal A: Cancer statistics, 2014. CA Cancer J Clin 2014;64:9-29. 